\title{
Cuestionamientos en torno al anuncio del sentido del fallo previsto en la legislación procesal civil colombiana
}

Questions about the Announcement of the Meaning of a Judgment Provided for in the Colombian Civil Procedural Legislation

Questões sobre o anúncio do significado da sentença provida na legislação processual civil colombiana

Luisa María Brito Nieto* 


\section{Resumen}

La legislación procesal civil colombiana prevé la figura del anuncio del sentido del fallo, en el evento en el que el juez opte por dictar la sentencia por escrito. La mencionada institución procesal encuentra importantes vacíos que han repercutido en que, en la práctica, se profieran anuncios del sentido del fallo incompletos y fundamentados en razones erróneas, en contravía del propósito de la figura. En adición, jurisprudencialmente se ha contemplado la posibilidad de cambiar en la sentencia escrita el sentido del fallo anunciado de manera previa, lo que contraría la legislación procesal civil y vulnera el derecho al debido proceso. En todo caso, y a pesar de no ser de frecuente utilización, existe un mecanismo procesal para lograr la completitud del anuncio del sentido del fallo, consistente en la solicitud de adición o complementación; y para atacar el cambio del sentido del fallo anunciado en la sentencia escrita por vulneración del debido proceso, correspondiente al recurso de apelación-cuando este proceda-, y la acción de tutela, de manera subsidiaria y excepcional.

\section{Palabras clave}

Sentencia; anuncio del sentido del fallo; acto procesal; acto procesal complejo; parte resolutiva de la sentencia. 


\section{Abstract}

Colombian civil procedural legislation provides for the concept of the announcement of the meaning of a judgment when the judge chooses to render it in writing. The procedural institution has found substantial gaps resulting in incomplete or unfounded announcements of the meaning of a judgment, going against the purpose of the concept. In addition, case law has considered the possibility of changing in writing the meaning of a judgment announced, which contradicts civil procedural legislation and violates the right to due process. In any case, and despite not being frequently used, the procedural mechanism for completing the announcement of the meaning of a judgment is the request for addition or supplementation. Some remedies to object to changes in the meaning of the written judgment for violation of due process include the appeal - when applicable - and the writ for the protection of constitutional rights subsidiarily and exceptionally.

\section{Keywords}

Judgment; announcement of the meaning of a judgment; proceedings; complex proceedings; operative part of a judgment. 


\section{Resumo}

A legislação processual civil colombiana prevê o anúncio do significado do acórdão, caso o juiz opte por emitir a sentença por escrito. A referida instituição processual encontra lacunas importantes que tiveram impacto no efeito de que, na prática, são realizados anúncios incompletos do significado do acórdão e baseados em razões errôneas, indo contra a finalidade da figura. Além disso, jurisprudencialmente, a possibilidade de alterar, no acórdão escrito, o significado da decisão previamente anunciada foi contemplado, o que contraria a legislação processual civil e viola o direito ao devido processo legal. De qualquer forma, e apesar de não ser frequentemente utilizado, existe um mecanismo processual para alcançar a totalidade do anúncio do significado do acórdão, que consiste no pedido de acréscimo ou complementação, e para atacar a mudança de sentido da decisão anunciada no acórdão escrito por violação do devido processo legal, correspondente ao recurso - quando for o caso- e à ação de tutela, de forma subsidiária e excepcional.

\section{Palavras-chave}

Julgamento; anúncio do significado do julgamento; ato processual; ato processual complexo; parte operacional do julgamento. 
Sumario: Introducción. 1. El acto procesal denominado anuncio del sentido del fallo. 1.1. ¿Qué es el anuncio del sentido del fallo? 1.2. ¿Cuál es la finalidad del anuncio del sentido del fallo? 1.3. ¿Cuál es la naturaleza jurídica del anuncio del sentido del fallo? 1.4. ¿Cuál es el contenido que requiere el acto procesal del anuncio del sentido del fallo para entenderse como tal? 2. La cuestionable posibilidad de cambiar el sentido del fallo. 2.1. ¿En qué consiste la prerrogativa de cambiar el sentido del fallo? 2.2. ¿Cambiar el sentido del fallo contraría el ordenamiento jurídico colombiano? 2.2.1. El cambio del sentido del fallo contraría las disposiciones del CGP que rigen el anuncio del sentido del fallo y la sentencia. 2.2.2. El cambio del sentido del fallo viola las garantías procesales fundamentales. 3. Mecanismos procesales para atacar la sentencia y el acto procesal denominado anuncio del sentido del fallo. 3.1. Mecanismos procesales aptos para lograr que el anuncio del sentido del faIlo cumpla con su contenido legal, cuando el juez no lo ha atendido. 3.2. Mecanismos aptos para atacar el acto procesal complejo denominado sentencia, cuando no existe coherencia entre el anuncio del sentido del fallo y la sentencia proferida. Conclusiones. Bibliografía.

\section{Introducción}

El artículo 373 de la Ley 1564 de 2012 (Código General del Proceso - CGP) señala que la sentencia deberá dictarse oralmente en audiencia, de forma posterior a que las partes efectúen sus alegatos de conclusión. Sin embargo, la codificación procesal prevé una alternativa consistente en que el juzgador pueda proferir la sentencia por escrito dentro de los diez días hábiles siguientes a la audiencia, para lo cual deberá anunciar el sentido del fallo en dicha diligencia. En este último evento, el mismo estatuto normativo prevé que el administrador de justicia deberá realizar una breve exposición de los fundamentos de su decisión, dejar constancia expresa de las razones concretas que lo llevaron a dictar el fallo por escrito, e informar a la Sala Administrativa del Consejo Superior de la Judicatura.

No obstante, brillan por su ausencia, tanto en la legislación como en el desarrollo jurisprudencial de la figura, dos aspectos torales del anuncio del sentido del fallo como acto procesal, que resultan relevantes para que dicha institución sea utilizada de forma adecuada por los operadores judiciales, a saber: i) cuáles son los motivos atendibles para que el juzgador opte por dictar sentencia por escrito y anunciar el sentido del fallo en audiencia; y ii) en qué deberá consistir o qué deberá contener el anuncio del sentido del fallo para que sea considerado como tal. El vacío respecto de estos puntos ha llevado a que en la práctica se hagan anuncios del sentido del fallo escuetos e inacabados, lo que vulnera a las partes su derecho a conocer el sentido de la decisión. Con el fin de delimitar los dos anteriores aspectos, en el primer acápite de este artículo nos dedicaremos a estudiar el acto procesal denominado anuncio del sentido del fallo en cuanto a su concepto, finalidad, naturaleza jurídica y contenido para que sea entendido como tal.

Por otro lado, y como desarrollaremos a lo largo del escrito, si bien el anuncio del sentido del fallo hace parte de un acto procesal complejo denominado 
sentencia, jurisprudencialmente se ha previsto la posibilidad de que, en casos excepcionales -pero no definidos por la jurisprudencia ni la ley- el juzgador pueda cambiar en la sentencia escrita el sentido del fallo anunciado en audiencia. Con el fin de analizar de forma crítica dicha posibilidad, en el segundo acápite del presente escrito expondremos en qué consiste la alternativa del cambio del sentido del fallo, y esgrimiremos las razones por las cuales a nuestro juicio dicha prerrogativa excepcional va en contravía de la regulación procesal civil que rige el anuncio del sentido del fallo y resulta violatoria del derecho al debido proceso.

Finalmente, y teniendo en cuenta la problemática evidenciada en los dos primeros acápites, en el último a partado nos dedicaremos a determinar los mecanismos procesales procedentes para: i) lograr que el juez complete el anuncio del sentido del fallo que no cumple con los requisitos para que este se considere como tal; y ii) atacar la variación del sentido del fallo en la sentencia, debido a que dicha circunstancia resulta abiertamente violatoria del derecho al debido proceso.

Para llevar a cabo el estudio descrito, se utilizará una metodología crítica, tomando como sustento fuentes doctrinales y jurisprudenciales.

\section{El acto procesal denominado anuncio del sentido del fallo}

En el presente acápite se estudiará el concepto, la finalidad, la naturaleza jurídica y el contenido del acto procesal del anuncio del fallo contemplado en el artículo 373 del CGP, con el fin de analizar su alcance para, en el próximo apartado, estudiar la posibilidad que se ha previsto jurisprudencialmente de cambiar su sentido.

\section{1 ¿Qué es el anuncio del sentido del fallo?}

La regla general, y uno de los importantes aciertos del CGP, es que las sentencias dictadas en los procesos declarativos, así como en los procesos ejecutivos en el caso en el que el ejecutado haya formulado excepciones, se profieren oralmente en audiencia ${ }^{1}$, tanto las de única como las de primera y segunda instancia. ${ }^{2}$

1 Hernando Devis Echandía, Tratado de derecho procesal civil. Parte General, Tomo III. De los actos procesales, Bogotá, Temis, 1963, pp. 1, 32 y 292.

2 Hay excepciones a esta regla. Es posible dictar sentencia por escrito en los siguientes casos: 1) sentencias que se dictan con motivo del allanamiento, si se presenta antes de la audiencia inicial; 2) las que se deben dictar de inmediato en los casos expresamente señalados en la ley, cuando el demandado guarda silencio o no se opone, como el caso del proceso de restitución de inmueble arrendado; 3) en el caso de sentencias anticipadas a las que se refieren los numerales 1 y 3 del CGP; y 4) en los procesos de declaración de pertenencia y saneamiento de la pequeña propiedad rural o urbana contemplados en la Ley 1561 de 2012, Por la cual se establece 
Una vez se haya agotado la etapa correspondiente a los alegatos, debe dictarse la sentencia en la audiencia, la cual debe cumplir con los requisitos de forma y fondo previstos en los artículos 280 a 282 del CGP. ${ }^{3}$

No obstante, si no es posible dictar sentencia oral, el juzgador tiene la alternativa de proferir un acto procesal denominado anuncio del sentido del fallo, es decir, señalar su decisión de fondo e indicar brevemente sus argumentos. ${ }^{4}$ En ese caso, deberá dejar constancia de las razones expresas de por qué no fue posible dictar sentencia de forma oral e informar de dicha circunstancia al Consejo Superior de la Judicatura. ${ }^{5} \mathrm{Si}$ el juez adopta esta opción, la sentencia deberá proferirse por escrito dentro de los diez días siguientes a la celebración de la audiencia, y se notificará por estado.

En consecuencia, bajo esta alternativa, la sentencia se dicta en dos etapas (con las precisiones que haremos en los acápites posteriores respecto de este acto procesal): i) en audiencia, de forma oral, mediante el anuncio del sentido del fallo; y ii) por escrito, dentro de los diez días siguientes, por medio de la sentencia. ${ }^{6}$

Sin embargo, el CGP no es preciso, ni tampoco ha sido desarrollado con claridad por la jurisprudencia, en cuanto a si existen restricciones a la utilización de esta herramienta. Adicionalmente, tampoco es claro -en la práctica, principalmente- cuál debe ser el contenido del anuncio del sentido del fallo para poder entenderse como tal.

\section{2 ¿Cuál es la finalidad del anuncio del sentido del fallo?}

Para entender el funcionamiento del acto procesal del anuncio del sentido del fallo es preciso analizar a qué propósito obedece.

En primer lugar, debe diferenciarse entre lo que se considera como una regla técnica y un principio. Los principios son el norte del sistema procesal, no admiten contrarios, son permanentes, de obligatoria observancia e inmodificables. Por el contrario, las reglas técnicas hacen referencia a lineamientos que, al ser desarrollados bajo un contexto en específico, resultan útiles o no, dependiendo de la época o la comunidad a la cual pretenden aplicarse. ${ }^{7}$

un proceso verbal especial para otorgar títulos de propiedad al poseedor material de bienes inmuebles urbanos y rurales de pequeña entidad económica, sanear la falsa tradición y se dictan otras disposiciones.

3 Héctor Hernández, Estudios de derecho procesal civil general. Conforme con el Código General del proceso, Bogotá, Leyer, 2016, pp. 58, 161 y ss.

4 Jaime Azula, Manual de derecho procesal, Tomo III. Procesos de conocimiento, Bogotá, Temis, 2016, pp. 31-34 y 366.

5 Organismo encargado de administrar los recursos de la rama judicial. Sus principales funciones son de planeación y administración de la rama judicial. Disponible en: https://www.ramajudicial.gov.co/web/consejosuperior-de-la-judicatura

6 Hernández, Estudios de derecho procesal civil general. Conforme con el Código General del proceso, op. cit., pp. 161 y ss.

7 Hernán Fabio López, Código General del Proceso. Parte General, Bogotá, Dupré, 2019, pp. 108-112. 
De conformidad con el artículo 3 del CGP, "Las actuaciones se cumplirán en forma oral, pública y en audiencias, salvo las que expresamente se autorice realizar por escrito o estén amparadas por reserva" ${ }^{8}$ En ese sentido, el CGP contempla por un sistema mixto, es decir, no se optó en su totalidad por la regla técnica de la oralidad ${ }^{9}$ ni tampoco por la escritura, al permitirse llevar a cabo actuaciones de forma escrita como excepción a la oralidad.

De acuerdo con la regla técnica de la oralidad, las actuaciones que se lleven a cabo en el transcurso del proceso se surten de forma verbal, dejándose registro mediante un sistema de grabación y constancia escrita solamente de los aspectos más relevantes..$^{10}$ En ningún caso se harán transcripciones del contenido de las grabaciones. ${ }^{11}$

Aunado a ello, la oralidad genera las circunstancias propicias para imprimir celeridad al proceso judicial, con miras a superar la congestión judicial, que es uno de los más grandes inconvenientes de los que ha padecido el sistema judicial en Colombia. ${ }^{12}$

A nuestro juicio, en la práctica no existe una clara preponderancia entre lo oral o lo escritural, simplemente existen determinadas actuaciones que la ley procesal prevé que se llevarán a cabo mediante uno u otro sistema. ${ }^{13} \mathrm{Si}$ bien el artículo 3 del CGP dispone que las actuaciones se llevarán a cabo de forma oral y por audiencias, lo cierto es que existe una importante cantidad de actuaciones que, de acuerdo con la misma legislación procesal, deberán acontecer por fuera de audiencia y, por tanto, se tramitarán por escrito. ${ }^{14}$

Por otro lado, otra regla técnica que rige nuestro sistema procesal colombiano -y que tiene relación con la materia bajo estudio- es la de la inmediación. De acuerdo con el artículo 6 del CGP, el juez deberá practicar de forma personal todas las pruebas y realizar de manera presencial las demás actuaciones que se adelanten en el proceso. ${ }^{15}$ Precisamente, una de las grandes ventajas del modelo actual es facilitar el contacto del juez con las partes y con las pruebas practicadas en el proceso.

8 Véase también Corte Suprema de Justicia, Sala de Casación Civil, Sentencia STC14870-2017 del 20 de septiembre de 2017, M. P. Luis Armando Tolosa Villabona.

9 Las audiencias y diligencias deberán llevarse a cabo de conformidad con las reglas previstas en el artículo 107 del CGP.

10 Eduardo Oteiza, “El juez ante la tensión entre libertad e igualdad”, en D. Agudelo et al. (dirs.), Derecho Procesal contemporáneo: perspectivas y desafios, Medellín, Universidad de Medellín, 2017, pp. 13-30.

11 Numeral segundo del artículo 103, numerales cuarto y sexto del artículo 107 del CGP. Véase también Carlos Naranjo, Derecho Procesal Civil. Parte General, Bogotá, Dike, 2016, pp. 50, 76 y 388.

12 Corte Constitucional, Sentencia C-713 de 2008, M. P. Clara Inés Vargas Hernández.

13 De acuerdo con López, el sistema procesal civil colombiano, desde el punto de vista práctico, es predominantemente escritural (López, Código General del Proceso. Parte General, op. cit.).

14 A manera de ejemplo, la demanda, su admisión y la contestación se tramitan, por regla general, de forma escrita. Véase Miguel Enrique Rojas, Lecciones de derecho procesal, Tomo 1. Teoría del proceso, Bogotá, Esaju, 2017, p. 295.

15 Lo anterior, sin perjuicio de lo establecido respecto de las pruebas extraprocesales, las pruebas trasladadas y demás excepciones previstas en la ley. Véanse artículos 6 y 171 del CGP. 
La inmediación alimenta el interés del administrador de justicia en el conflicto que está llamado a resolver, pues este dirige la actividad probatoria, lo cual le facilita, precisamente, la emisión de la sentencia, pues le permite el recuerdo del debate probatorio, sin requerir repasar actas o grabaciones para llevar a cabo su labor. Por ello, la sentencia está llamada a ser dictada de forma inmediata, luego de la confrontación, dentro de la misma audiencia sin solución de continuidad, en un proceso íntegramente concentrado. ${ }^{16}$

En concordancia con lo anterior, el artículo 5 del CGP preceptúa la regla de la concentración, consistente en que el juez deberá programar las audiencias y diligencias de forma que el objeto de cada una se cumpla sin solución de continuidad, es decir, de forma concentrada. ${ }^{17}$ Lo anterior tiene mucho sentido, dado que el transcurso de los días entre la culminación de la etapa probatoria y la emisión de la sentencia oscurece los recuerdos del juzgador, obligándolo a acudir a actas y grabaciones para emitir su fallo. ${ }^{18}$

Ahora bien, en desarrollo de estas reglas técnicas, el CGP ha previsto que, por regla general, las sentencias se dictarán de forma oral. Sin embargo, lo anterior no cercena la posibilidad de que el juez, en los casos en los que considere necesario, pueda proferir la sentencia por escrito. Como veremos, al tener que anunciar el sentido del fallo en audiencia, se generan una serie de inconvenientes a nivel práctico, principalmente, en torno a cuál debería ser su contenido y qué pasaría en el caso en el que el juzgador cambie de opinión una vez estudiado el asunto.

\section{3 ¿Cuál es la naturaleza jurídica del anuncio del sentido del fallo?}

El acto jurídico supone una conducta desarrollada por el ser humano con la voluntad de alcanzar ciertos fines jurídicos. ${ }^{19}$ Ahora bien, dentro del género de los actos jurídicos se encuentran los actos procesales. El acto jurídico procesal ${ }^{20} \mathrm{es}$ aquel que tiene importancia jurídica respecto de la relación procesal, dado que tiene consecuencias en la constitución, modificación o definición de la relación procesal y que puede provenir de cualquiera de los sujetos de esta, es decir, de las partes o del administrador de justicia. ${ }^{21}$ Lo anterior quiere decir que la

16 Corte Constitucional, Sentencia C-124 de 2011, M. P. Luis Ernesto Vargas Silva; Corte Constitucional, Sentencia C-543 de 2011, M. P. Humberto Antonio Sierra Porto.

17 No podrá aplazar una audiencia o diligencia, ni suspenderla, salvo por las razones que expresamente autoriza este código. Véanse artículo 5, numeral segundo del artículo 197 y numeral primero del artículo 373 del CGP.

18 Rojas, Lecciones de derecho procesal, op. cit., pp. 389 y ss.

19 Gustavo Calvinho, "El acto procedimental", en G. Hernández, Derecho procesal moderno. Distintas visiones

$408 \quad 20 \quad$ alrededor de esta disciplina, Bogotá, Universidad Externado de Colombia, 2013, pp. 11 y 31.

21 Giuseppe Chiovenda, Principios de derecho procesal civil, Madrid, Reus, 1922, p. 230; Hernando Morales, Curso de derecho procesal civil. Parte general, Bogotá, ABC, 1991, pp. 316 y ss. 
característica propia de los actos procesales es que surten efectos solo dentro del proceso en el que se ejecutan. ${ }^{22}$ En ese orden de ideas, los actos procesales dan lugar al inicio del proceso y transcurren o son consecuencia de este. ${ }^{23}$ El acto procesal más relevante, proveniente del juez, es la sentencia. La sentencia es un acto que define la relación procesal, consistente en la resolución del operador judicial, en la que se decide sobre las pretensiones de la demanda y las excepciones de mérito, cualquiera que sea la instancia en la que se dicte, así como las que resuelven los recursos de casación y revisión. ${ }^{24}$ En ese orden de ideas, la sentencia es un acto de composición procesal, toda vez que se da una vez el operador judicial ha adquirido y elaborado los elementos de juicio necesarios con los cuales va a resolver el litigio. ${ }^{25}$

Ahora bien, una de las clasificaciones de los actos procesales ha sido por su estructura. ${ }^{26}$ En ese sentido, se distinguen los actos procesales según consistan en uno o en varios actos concurrentes para la obtención de un solo efecto jurídico procesal. De acuerdo con lo anterior, existe un acto simple cuando la ejecución total de un solo acto procesal conlleva el efecto jurídico correspondiente. En cambio, se tratará de un acto complejo cuando para alcanzar el efecto jurídico procesal correspondiente es necesaria la concurrencia de varios actos que, en todo caso, permanecerán relacionados por su unidad o interdependencia de causa. ${ }^{27}$

De acuerdo con lo anterior, el acto procesal de anuncio del sentido del fallo hace parte de un acto procesal complejo llamado sentencia. Como se mencionó, de conformidad con el numeral 5 del artículo 373 del CGP, el juez tiene la alternativa de optar por dictar sentencia por escrito, anunciando el sentido del fallo de forma oral en audiencia. En ese orden de ideas, tanto el anuncio del sentido del fallo como el fallo dictado por escrito hacen parte de la sentencia, y los actos procesales que lo componen se encuentran relacionados y conforman una unidad inescindible.

En suma, bajo la normatividad procesal civil colombiana, el fallo es un todo indivisible y uniforme, conformado por: i) el anuncio del sentido del fallo; y ii) la sentencia dictada por escrito. Esto quiere decir que debe existir una unidad temática entre ambos actos procesales que constituyen uno complejo, por lo que sus alcances deberían coincidir. ${ }^{28}$

22 José Acosta, “Los hechos y actos procesales”, en El proceso ante el tribunal internacional de justicia, Barcelona, Bosch, en http://vlex.com/vid/hechos-actos-procesales-281811, fecha de consulta: 17 de abril de 2021.

23 Carlos Gallego y Natalia Jaramillo, Teoría general del proceso. Actualizada en concordancia con la Ley 1564 de 2012, Bogotá, lbáñez, 2018, pp. 179 y ss.

24 Jairo Parra, Derecho procesal civil, Tomo I. Parte general, Bogotá, Temis, 1992, p. 232

25 Echandía, Tratado de derecho procesal civil. Parte General, op. cit.

26 Las clasificaciones de los actos procesales son muy variadas. Entre otras, están según su efecto, finalidad y estructura (Echandía, Tratado de derecho procesal civil. Parte General, op. cit.).

27 Azula, Manual de derecho procesal, op. cit.

28 Corte Suprema de Justicia, Sala de Casación Penal, Sentencia del 3 de mayo de 2007, Rad. 26222. 


\section{4 ¿Cuál es el contenido que requiere el acto procesal del anuncio del sentido del fallo para entenderse como tal?}

De conformidad con el mencionado artículo 373 del CGP, ${ }^{29}$ para optar por la alternativa de dictar sentencia por escrito, el administrador de justicia deberá: i) dejar constancia expresa de las razones concretas de por qué dictará la sentencia por escrito; ii) informar al Consejo Superior de la Judicatura de esta circunstancia; iii) anunciar el sentido de su fallo; y iv) hacer una breve exposición de sus fundamentos. ${ }^{30}$

No obstante, si bien el CGP se cuidó en establecer los anteriores requisitos para el caso en el que el operador judicial opte por anunciar el sentido del fallo y dictar la sentencia por escrito, a nuestro juicio, resultan bastantes ambiguos -tanto en la teoría como en la práctica- dos de estas exigencias: i) las razones por las cuales el juez puede optar por esta opción; y ii) qué quiere decir anunciar el sentido del fallo. ${ }^{31}$ Vamos a analizar cada uno de ellos.

En primera instancia, debe mencionarse que la norma no indica razones taxativas ni enunciativas para optar por la alternativa de anunciar el sentido del fallo y dictar, posteriormente, sentencia por escrito. No obstante, es preciso indicar que estas razones, en nuestro criterio, no podrán corresponder en manera alguna a que el juzgador no tenga plenamente formado su convencimiento acerca de la decisión, ya que, como se mencionará, deberá señalarse de forma precisa la parte resolutiva de la sentencia. Sencillamente, si el administrador de justicia no se encuentra convencido $y$, por tanto, considera que no puede dictar sentencia, tampoco podrá anunciar el sentido del fallo..$^{32}$ Por ello precisamente el CGP prevé la posibilidad de que el operador judicial realice un receso de hasta dos horas, con el fin de que dilucide las dudas que puedan haberle surgido en la audiencia respecto de la decisión que debe tomar, sin perjuicio de que tiene el deber de asistir a la audiencia con el pleno conocimiento del expediente y del asunto que está llamado a dirimir.

Así las cosas, los motivos que podrá aducir el juzgador para optar por el anuncio del sentido del fallo deberán ser distintos, por ejemplo, por razones de tiempo en cuanto a la lectura del fallo o con el fin de preparar de forma adecuada la parte motiva de la sentencia, sin que esto implique que no tenga seguridad de la decisión que va a tomar. En todo caso, tampoco menciona el

30 David Guette, "El sentido del fallo contemplado en el artículo 373.5 del Código General del Proceso: lo inane de la figura", en Revista de Derecho Privado 36 (2019), pp. 259-279.

31 A diferencia de la materia penal, donde debe indicarse el delito específico del cual se absuelve o se condena, de conformidad con el artículo 446 de la Ley 906 de 2004, Por la cual se expide el Código de Procedimiento Penal.

32 Marco Antonio Álvarez, Cuestiones y opiniones. Acercamiento práctico al Código General del Proceso, Bogotá, Colegio de Jueces y Fiscales de Tunja, 2017, pp. 269, 11, 12, 168. 
CGP si estas razones podrán ser controvertidas, asunto que será objeto de estudio en acápites posteriores de este escrito.

Por otro lado, la exigencia de que el juez deba anunciar el sentido del fallo obedece a que las partes tienen derecho a que, si no se profiere sentencia en audiencia, al menos puedan conocer el sentido del fallo y saber quién de ellos tuvo la razón y resultó vencedor. ${ }^{33}$

En concordancia con lo mencionado en el acápite precedente, el anuncio del sentido del fallo hace parte de la sentencia misma. ${ }^{34}$ Así las cosas, y teniendo en cuenta que con el anuncio del sentido del fallo se busca que las partes conozcan quién resultó vencedor en el proceso, el contenido de este acto procesal deberá ser la parte resolutiva de la sentencia, es decir, deberá indicarse de forma precisa y específica si se accedió -total o parcialmente- o no a las pretensiones y si prosperó alguna excepción de mérito. En ese sentido, no podrá considerarse como anuncio del sentido del fallo, por ejemplo, el señalamiento por parte del operador judicial de que se accede "parcialmente" a las pretensiones, pero sin indicar de forma precisa a cuáles y en qué medida.

Ahora bien, y tal como lo prevé la norma, el señalamiento de la parte resolutiva del fallo deberá ir acompañado de una breve exposición de la parte motiva, sin perjuicio de que el análisis respectivo sea consignado en la sentencia que se dictará por escrito.

\section{La cuestionable posibilidad de cambiar el sentido del fallo}

Habiendo analizado el acto procesal denominado anuncio del sentido del fallo, nos concierne estudiar la cuestionable posibilidad que ha surgido jurisprudencialmente de variar dicho anuncio en la sentencia que se dicta por escrito, aun cuando en este se haya dispuesto otra cosa. Para ello, expondremos en qué consiste esta posibilidad y determinaremos si esta viola de algún modo el derecho fundamental al debido proceso.

\section{1. ¿En qué consiste la prerrogativa de cambiar el sentido del fallo?}

Para responder el interrogante planteado, analizaremos la jurisprudencia de la Corte Suprema de Justicia en torno a la posibilidad de cambiar el sentido del fallo una vez ha sido anunciado.

\footnotetext{
33 Idem.

34 Lo anterior implicará que deban anunciarse también los salvamentos o las aclaraciones de voto, sin perjuicio de que se expresen las razones de ello de forma escrita, ya que en la audiencia solo será escuchado el magistrado sustanciador (idem).
} 
A través de la sentencia del 21 de marzo de $2018,{ }^{35}$ la Sala de Casación Civil de la Corte Suprema de Justicia resolvió una acción de tutela instaurada en contra del Tribunal Superior de Distrito Judicial de Bogotá, mediante la cual se reprochaba una vía de hecho en virtud de haberse modificado en la sentencia escrita el sentido del fallo emitido en la audiencia. En ese orden de ideas, el accionante indicó que existía una incongruencia entre el acto procesal del anuncio del sentido del fallo y la sentencia.

En el caso concreto, en la audiencia, de forma posterior a escuchar las alegaciones de las partes, el operador de justicia manifestó que se dictaría sentencia de segunda instancia de forma escrita, ya que se trataba de un asunto extenso y con varios problemas jurídicos por resolver. En este punto es relevante mencionar que, en concordancia con lo mencionado en acápites anteriores, resulta erróneo a nuestro juicio que la Sala de Casación Civil haya considerado estas razones como atendibles para dictar el fallo por escrito, dado que de ninguna manera optar por dicha alternativa se puede justificar en que la cuestión por resolver resulte bastante compleja, puesto que para ello el administrador de justicia cuenta con la posibilidad de decretar un receso con el fin de dilucidar las dudas que pueda tener, $\mathrm{y}$, en todo caso, debió asistir a la audiencia con el suficiente conocimiento del asunto sometido a su decisión.

Ahora bien, en la sentencia citada, por las razones expuestas, se anunció que el fallo sería modificatorio de la sentencia de primera instancia, que se extendería la condena al pago de perjuicios a la aseguradora, y que en todo lo demás que no hubiere lugar a modificar, se confirmaría lo dictado por el juez de primera instancia. Sin embargo, al momento de dictarse sentencia por escrito, la sala acogió la excepción propuesta por los demandados denominada "compensación de culpas" y redujo la condena inicial.

Por ello, los demandantes presentaron la mencionada acción de tutela, aduciendo que no era admisible la modificación del sentido del fallo anunciado en la sentencia escrita, ya que dicha circunstancia vulnera el derecho fundamental al debido proceso, al resultar a todas luces incoherente e incongruente el anuncio del sentido del fallo con la sentencia que fue proferida por escrito. Para resolver la cuestión descrita, la alta corporación estudió si este tipo de pronunciamiento transgredía los derechos fundamentales del accionante. Como primera medida, la Corte consideró que estrictamente el sentido del fallo no fue modificado, ya que en audiencia se anunció que todo aquello que no fuera necesario modificar, se confirmaría. Es preciso en este punto anotar que, según lo analizado en el acápite precedente, dicha aseveración no satisface lo que debería contener el anuncio del sentido del fallo ni su finalidad, consistente

35 Corte Suprema de Justicia, Sala de Casación Civil, Sentencia STC3984-2018 del 21 de marzo de 2018, M. P. Luis Alfonso Rico Puerta; Corte Suprema de Justicia, Sala de Casación Laboral, Sentencia STL6431-2018 del 9 de mayo de 2018, M. P. Clara Cecilia Dueñas Quevedo. 
en que las partes conozcan la parte resolutiva de la sentencia, sino que, por el contrario, resulta ser un sentido del fallo bastante oscuro e insuficiente, circunstancia que infortunadamente se ha tornado bastante común en la práctica. Además, la Corte concluyó que con la decisión cuestionada no se violaba ningún derecho fundamental, ya que no existe causal de nulidad alguna que sancione este evento. ${ }^{36}$ Aunado a ello, afirmó que una pauta de procedimiento de carácter instrumental, como lo es el acto procesal del anuncio del sentido del fallo, no puede restringir al juez variar el sentido de la decisión si de no hacerlo está cercenando un derecho sustancial, teniendo en cuenta que existe una prevalencia de este en la interpretación de las normas procesales. ${ }^{37}$

Así las cosas, la Corte Suprema de Justicia aseveró que es viable variar el sentido del fallo y dictar por escrito una sentencia diferente a la anunciada, ya que no existe disposición normativa alguna que lo impida o sancione. En todo caso, a juicio de la Corte, dicha situación no constituye por sí sola una vulneración de las garantías procesales contempladas en nuestro ordenamiento jurídico, ni tampoco implica la invalidez de la decisión.

No obstante, es preciso mencionar que la Corte advirtió que la variación del sentido del fallo se debe presentar en casos excepcionalísimos, sin indicar cuáles ni con qué criterios identificarlos, y que el juzgador deberá argumentar de forma suficiente el porqué de la variación.

Así mismo, la alta corporación recalcó que las reglas técnicas preponderantes en el sistema procesal civil colombiano son las de la oralidad, inmediación y concentración, por lo que, de igual modo, deberá procurarse por el ideal de que los fallos sean dictados en audiencia y que la excepcional medida sustituta de anunciar el sentido del fallo para posteriormente dictar la sentencia por escrito no podrá volverse la regla general, como en efecto está sucediendo en la práctica.

\section{2. ¿Cambiar el sentido del fallo contraría el ordenamiento jurídico colombiano?}

A nuestro juicio, la figura del cambio del sentido del fallo-contemplada, claro está, de forma jurisprudencial y no legal- contraría el ordenamiento jurídico colombiano, principalmente por dos razones: i) va en contra de lo dispuesto en la legislación procesal civil respecto de las reglas que rigen el anuncio del sentido del fallo y la sentencia; y, como si esto fuera poco, i) vulnera las garantías procesales de las partes. Vamos a analizar cada una de estas razones.

36 Causales taxativas contempladas en el artículo 133 del CGP.

37 Artículo 11 del CGP. 


\subsubsection{El cambio del sentido del fallo contraría las disposiciones del CGP que rigen el anuncio del sentido del fallo y la sentencia}

Tal como se puso de presente, el anuncio del sentido del fallo y la sentencia dictada por escrito constituyen un acto procesal de carácter complejo, por lo que son inescindibles. ${ }^{38}$ Así las cosas, si se atiende a lo dispuesto por el artículo 285 del CGP, la sentencia no es revocable ni modificable por parte del juzgador que la pronunció, ${ }^{39}$ lo cual implica que tampoco puede desconocerse el sentido del fallo anunciado, ya que hace parte de la sentencia misma como acto procesal de carácter complejo.

Existe entonces una clara dependencia entre el anuncio del sentido del fallo y la providencia finalmente emitida por escrito, dado que el CGP no solamente exige al funcionario judicial anticipar el sentido de su decisión, sino realizar una breve exposición de sus fundamentos. ${ }^{40}$

Adicionalmente, no puede perderse de vista que en el lapso de tiempo que transcurra desde el anuncio del sentido del fallo hasta la emisión de la sentencia por escrito no existe un nuevo periodo probatorio ni tampoco una nueva oportunidad para presentar alegaciones finales, razón por la cual no habría motivos para que exista una variación en la decisión del administrador de justicia. ${ }^{41}$

Por otro lado, la misma codificación procesal diseñó la estructura del proceso de forma tal que el juez cuente con las oportunidades procesales necesarias para forjar su convencimiento, sin tener que cambiar el sentido del fallo anunciado. El juicio mental ${ }^{42}$ que realiza el juez con el fin de emitir sentencia se realiza en varias fases, las cuales se dan, según la estructura prevista en el CGP, en una buena parte, de forma previa a la audiencia en la que debe dictarse fallo, momento en el que el operador judicial exterioriza su razonamiento. ${ }^{43}$

De esta manera, es claro que la preparación del juez respecto del caso de forma previa a la audiencia es fundamental para que este se encuentre en capaci-

38 Corte Suprema de Justicia, Sala de Casación Civil, Sentencia del 25 de septiembre de 2013, M. P. Fernando Alberto Castro Caballero, Rad. 40334. Véase también, Alfonso Daza, “Comentario II. ¿Se puede anular el sentido del fallo después de lo anunciado en la respectiva sentencia?", en Estudios críticos de jurisprudencia de la Corte Suprema de Justicia 2 (2013), pp. 57-83.

39 Salvo por las figuras de la aclaración, corrección y adición contempladas en los artículos 285 y siguientes del CGP, que tienden a enmendar yerros en la providencia con el fin de evitar entorpecer el futuro cumplimiento de la sentencia, mas no cambiar su sentido.

40 Corte Suprema de Justicia, Salvamento de Voto, M. P. Aroldo Wilson Quiroz Monsalvo, Rad. 11001-02-03000-2018-00041-00. Corte Suprema de Justicia, Sala de Casación Civil, Sentencia del 21 de marzo de 2018, M. P. Luis Alfonso Rico Puerta, Rad. STC3984-2018.

41 Daza, “Comentario II. ¿Se puede anular el sentido del fallo después de lo anunciado en la respectiva sentencia?", op. cit.

$414 \quad 42$ En el cual realiza una elección entre las distintas alternativas posibles, dependiendo de la disposición normativa por aplicar, los hechos que resultaron probados y acreditados en el proceso, entre otras cosas.

43 Guette, "El sentido del fallo contemplado en el artículo 373.5 del Código General del Proceso: lo inane de la figura", op. cit. 
dad de dictar sentencia o anunciar el sentido del fallo -que hace parte del acto complejo llamado sentencia-, obedeciendo a las reglas técnicas que inspiran nuestra legislación procesal civil, tales como la oralidad, la inmediación y la concentración.

Adicionalmente, es necesario mencionar una vez más que el artículo 373 del CGP contempla la posibilidad de que el juzgador decrete un receso de hasta dos horas, tiempo suficiente para dilucidar, en conjunto con el personal que lo acompaña, las dudas que hubieren podido surgirle durante la audiencia, puesto que es claro que las dudas previas a esta debió absolverlas en su momento y asistir plenamente preparado a la diligencia.

\subsubsection{El cambio del sentido del fallo viola las garantías procesales fundamentales}

A nuestro juicio, alterar el sentido del fallo vulnera el derecho al debido proceso contemplado en el artículo 29 de la Constitución Política, derecho fundamental que consiste en el conjunto de garantías previstas en el ordenamiento jurídico, las cuales tienen como fin la protección de los asociados incursos en actuaciones judiciales o administrativas, para que durante su trámite se respeten sus derechos y se logre la efectiva y adecuada administración de justicia. ${ }^{44}$ En ese orden de ideas, el derecho al debido proceso tiene como objeto la preservación de la justicia material. ${ }^{45}$

En ese orden de ideas, desde luego, contraría el derecho al debido proceso el hecho de que el operador judicial culmine una audiencia haciendo creer a las partes que el vencedor en el proceso ha sido la parte demandante o la parte demandada -toda vez que es su derecho conocer el sentido de la decisión en tal oportunidad procesal-, y que posteriormente, al dictarse sentencia por escrito, sean sorprendidos con una decisión completamente distinta. De permitirse cambiar el sentido del fallo, se estarían afectando los principios de transparencia, seguridad jurídica y confianza legítima, los cuales irradian nuestro sistema jurídico en general y son parte del derecho al debido proceso. ${ }^{46}$

En consecuencia, debe garantizarse a los asociados que el Estado no los va a sorprender con actuaciones que, analizadas aisladamente, tengan un fundamento, pero que, al compararlas resulten contradictorias, en virtud de que la decisión inicial genera expectativas legítimas, las cuales deben respetarse. ${ }^{47}$

44 Corte Constitucional, Sentencia C-341 de 2014, M. P. Mauricio González Cuervo. Véase también, Naranjo, Derecho Procesal Civil. Parte General, op. cit.

45 Corte Constitucional, Sentencia C-641 de 2002, M. P. Rodrigo Escobar Gil; Corte Constitucional, Sentencia T-115 de 2018, M. P. Alberto Rojas Ríos.

46 Álvarez, Cuestiones y opiniones. Acercamiento práctico al Código General del Proceso, op. cit.

47 Corte Suprema de Justicia, Sala de Casación Civil, Auto del 4 de febrero de 2008, Exp. 2002-00537-00. 


\section{Mecanismos procesales para atacar la sentencia y el acto procesal denominado anuncio del sentido del fallo}

Hace parte del ejercicio del derecho de acción y del derecho al debido proceso la facultad con la que cuentan las partes de solicitar a la administración de justicia la revisión y nuevo análisis de las providencias proferidas por el operador judicial. Esta facultad consiste, desde un punto de vista amplio, en la formulación de solicitudes a la administración de justicia con el fin de obtener nuevos juicios o análisis sobre una o varias cuestiones que han sido objeto de decisión mediante una providencia judicial. Lo anterior se justifica en la medida en que la actividad jurisdiccional es encomendada a seres humanos, cuyo conocimiento y discernimiento son claramente falibles. ${ }^{48}$

En el presente acápite se pretende determinar qué mecanismos previstos en la legislación procesal civil resultan aptos para atacar la sentencia y el acto procesal denominado anuncio del sentido del fallo, en los siguientes eventos: i) cuando el juzgador no satisface los requisitos que debe cumplir el contenido del anuncio del sentido del fallo, conforme a lo analizado en acápites precedentes; y ii) cuando no existe coherencia entre el anuncio del sentido del fallo y la sentencia proferida por escrito -es decir, entre los actos procesales que conforman el acto procesal complejo denominado sentencia-, debido a que el administrador de justicia ha cambiado su sentido.

\subsection{Mecanismos procesales aptos para lograr que el anuncio del sentido del fallo cumpla con su contenido legal, cuando el juez no lo ha atendido}

Podrá solicitarse al juez que el acto procesal del anuncio del sentido del fallo cumpla con su contenido, en el evento en el que el operador judicial no lo haya satisfecho. Como fue mencionado, en el acto procesal denominado anuncio del sentido del fallo deberá indicarse:

i. Los motivos por los cuales no resulta posible dictar sentencia de forma oral, razones que en todo caso no podrán corresponder a tener dudas sobre la controversia que se va a fallar.

ii. Parte resolutiva del fallo, de forma concreta y específica.

iii. Una breve exposición de los motivos de la decisión.

48 Ugo Rocco, Tratado de Derecho Procesal Civil. Parte Especial. Proceso de cognición, Bogotá, Temis, 1972, pp. 311 y ss. 
En relación con lo anterior, y a nuestro juicio, de forma desafortunada, la ley procesal no contempla mecanismo procesal alguno para cuestionar los motivos aducidos por el operador judicial para dictar la sentencia por escrito, habida cuenta de que:

i. Las razones que exponga el juzgador para dictar la sentencia por escrito no constituyen un acto procesal independiente, separado, ni mucho menos previo al anuncio del sentido del fallo, por lo que no podría controvertirse de forma previa a que este sea dictado.

ii. La finalidad de atacar los motivos en los que se basa el operador judicial es lograr que la decisión sea dictada oralmente, al no existir razones que lo fundamenten, o que se aduzcan otras, fin que no podría lograrse habiéndose ya anunciado el sentido del fallo, teniendo en cuenta lo mencionado en el anterior literal.

iii. Carecería de todo sentido que las partes pudieran atacar los motivos esgrimidos por el administrador de justicia de forma posterior a que se anuncie el sentido del fallo, toda vez que podrían ser utilizados por una parte u otra dependiendo de si la decisión le resulta o no favorable.

Por otro lado, es preciso enfatizar que esta no es la oportunidad procesal para cuestionar el sentido de la decisión mediante la interposición de algún recurso, comoquiera que este acto procesal no es la sentencia misma, sino que deberá esperarse hasta que esta se dicte de forma escrita y se configure la sentencia para ejercer los medios de impugnación del caso.

Ahora bien, conviene preguntarnos ¿qué mecanismo procesal podrá ejercerse por las partes en el supuesto en el que el anuncio del sentido del fallo resulte incompleto, por no señalar de forma expresa la parte resolutiva del fallo o por no realizarse una breve exposición de la parte motiva? No puede perderse de vista que en el evento bajo estudio, la providencia no provoca inconformidad en sí misma por las partes ni se pretende la revocación o reforma de la decisión, por lo que no podremos hacer referencia a un medio de impugnación.

A pesar de no ser de común ocurrencia que las partes realicen solicitudes respecto del anuncio del sentido del fallo, sino que, por su incompletitud, suelen aguardar hasta la notificación de la sentencia, estas claramente podrán solicitar la adición de la providencia, consagrada en el artículo 287 del CGP.

La adición de providencias procede en el caso en el que el juez omita resolver sobre algún aspecto que debía ser definido en la providencia que pretende adicionarse, ya sea por haber sido planteado por las partes, o porque la ley 
dispone que debe ser objeto de pronunciamiento, como sucede en el asunto bajo estudio. ${ }^{49}$

A nuestro juicio, cualquiera de las partes podrá solicitar la adición del anuncio del sentido del fallo de forma inmediata, toda vez que, como fue expuesto, este es proferido en audiencia, so pena de que se considere extemporánea. En virtud de la solicitud presentada, el operador judicial deberá proferir un auto en audiencia que adicione el anuncio del fallo, de forma que cumpla con los requisitos de contenido especificados de forma precedente..$^{50}$

Veamos un ejemplo. Piénsese en el evento en el que, escuchados los alegatos de las partes, el operador judicial manifiesta que no hará uso de su derecho a decretar un receso de hasta dos horas para el pronunciamiento de la sentencia, sino que procederá a anunciar su sentido y a dictarla por escrito dentro de los diez días hábiles siguientes, de conformidad con el artículo 373 del CGP. Para ello, indica que:

i. Por razones de tiempo, dado que se encuentra ad portas de iniciar otra audiencia, deberá dictarla por escrito.

ii. Se accederá o no a las pretensiones dependiendo de los hechos que se encuentren probados.

iii. Informará de su decisión a la Sala Administrativa del Consejo Superior de la Judicatura.

Notificado este auto por estrados, cualquiera de las partes, al evidenciar que el contenido de este acto procesal se encuentra evidentemente incompleto, podrá solicitar su adición o complementación, con el fin de que el administrador de justicia indique, de forma certera, cuál es el sentido del fallo, es decir, en nuestro ejemplo:

i. Si se accede o no a las pretensiones de la demanda, y de accederse de forma parcial, a cuáles de ellas.

ii. Dé una breve exposición de los motivos de esta decisión.

En consecuencia, y se itera, a pesar de su poca o nula ocurrencia, las partes sí cuentan con un mecanismo procesal para solicitar que el anuncio del sentido del fallo se realice de forma completa y no, como suele acontecer, se profiera uno escueto e inacabado.

49 Miguel Enrique Rojas, Lecciones de Derecho Procesal, Tomo 2. Procedimiento Civil, Bogotá, Esaju, 2016, pp. 60-61. 50 Luis Osorio, Manual de Derecho Procesal Civil. Parte General, Bogotá, Leyer, 2016, pp. 204 y 279. 


\subsection{Mecanismos aptos para atacar el acto procesal complejo denominado sentencia, cuando no existe coherencia entre el anuncio del sentido del fallo y la sentencia proferida}

Consideramos que cuando no existe coherencia entre el anuncio del sentido del fallo y la sentencia proferida, debido a que el operador judicial ha cambiado su sentido, existen mecanismos procesales aptos con el fin de controvertir dicho acto -conformado por el anuncio del sentido del fallo y la sentencia dictada por escrito-. Ahora bien, en el presente apartado estudiaremos los mecanismos que resultan viables con el propósito de controvertir la discrepancia entre el anuncio del sentido del fallo y la sentencia dictada por escrito, mas no el contenido mismo de la decisión de uno u otro.

Como primera medida, los involucrados podrán interponer recurso de apelación en contra de la sentencia, claro está, solamente si esta es apelable. ${ }^{51}$ Ahora bien, para ello, deberán cumplirse los presupuestos procesales para que alguna de las partes pueda ejercer este mecanismo de impugnación, toda vez que las normas procesales no reconocen a todos los individuos y en todos los supuestos la facultad o posibilidad jurídica de impugnar las providencias. $^{52}$

Principalmente, y en relación con la materia objeto de estudio, nos interesa el requisito relativo a que deberá recurrir dicho acto procesal quien tenga interés para ello. Se tendrá interés o legitimación para recurrir si se ha sido derrotado en el proceso, es decir, si se ha perdido la causa, comoquiera que en la sentencia no se han visto acogidas las pretensiones o excepciones formuladas. ${ }^{53}$ Así las cosas, si bien es innegable que a ambas partes se les vulnera el debido proceso por el solo hecho de habérseles variado el sentido del fallo, solamente tendrá interés para recurrir, ya sea el demandante o el demandado, según las reglas que se formulan a continuación, entre otras cosas, ya que no resultaría lógico ni razonable que quien no se vio perjudicado con la sentencia interponga el respectivo recurso:

i. Si en el anuncio del sentido del fallo se acogieron las pretensiones, y en la sentencia dictada por escrito no, el demandante tendrá interés para recurrir.

$51 \quad$ Artículo 321 del CGP: "Son apelables las sentencias de primera instancia, salvo las que se dicten en equidad".

52 Alejandro Gallo, Recursos y nulidades procesales en el Código General del Proceso, Bogotá, Leyer, 2018, pp. 11, 123 y 127; Antonio Pardo, Tratado de Derecho Procesal Civil, Antioquia, Editorial de la Universidad de Antioquia, 1956, pp. 80 y 182; Pedro Pablo Cardona, Los recursos ordinarios y extraordinarios en el derecho procesal civil, Bogotá, Leyer, 2011, pp. 7 y 11.

53 Edgar Escobar, Los recursos en el Código General del Proceso, Medellín, Librería Jurídica Sánchez R., 2015, p. 21. Véase también Jaime Azula, Manual de Derecho Procesal, Tomo II. Parte General, Bogotá, Temis, 2015, pp. 257 y 286. 
ii. Si en el anuncio del sentido del fallo se acogieron parcialmente las pretensiones, y en la sentencia dictada por escrito no se accedió a ninguna, el demandante tendrá interés para recurrir.

iii. Si en el anuncio del sentido del fallo se acogieron parcialmente las pretensiones, y en la sentencia dictada por escrito se acogieron la totalidad de las pretensiones, el demandado tendrá interés para recurrir.

iv. Si en el anuncio del sentido del fallo no se accedió a las pretensiones, y en la sentencia dictada se acogieron parcialmente, ambas partes tendrán interés para recurrir.

v. Si en el anuncio del sentido del fallo se acogieron las pretensiones, y en la sentencia dictada se acogieron parcialmente, ambas partes tendrán interés para recurrir.

vi. Si en el anuncio del sentido del fallo se negaron las pretensiones, y en la sentencia dictada por escrito se acogieron, el demandado tendrá interés para recurrir.

Por otro lado, el recurrente deberá formular los correspondientes reparos concretos, habida cuenta de que el CGP asumió el sistema de pretensión impugnaticia y no de competencia panorámica, ${ }^{54}$ dentro de las cuales deberá referirse expresamente a la incoherencia entre el anuncio del sentido del fallo y el fallo dictado de forma escrita.

Ahora bien, es preciso mencionar que este es el único recurso con el que cuentan las partes para controvertir la discrepancia entre dichos actos procesales que conforman el acto procesal complejo denominado sentencia, habida cuenta de que este supuesto no está cobijado por las causales específicas del recurso de casación.

Por otro lado, es preciso analizar si, eventualmente, cabría la posibilidad de alegar una nulidad frente a esta circunstancia que, a nuestro juicio y como lo mencionamos, resulta violatorio del derecho al debido proceso.

La nulidad es una sanción que tiende a privar de efectos a un acto procesal en cuya ejecución no se han acatado ciertas normas. En ese orden de ideas, mediante la nulidad lo que se pretende es invalidar el acto por no haberse seguido las formas procesales esenciales y de garantía, si con dicho desconocimiento se ha vulnerado el derecho al debido proceso ya que, de lo contrario, producirá efectos. ${ }^{55}$ derecho procesal civil, op. cit. 
Sin duda alguna, existe un vínculo fundamental y estrecho entre el derecho fundamental al debido proceso y la institución de las nulidades procesales, comoquiera que su finalidad última es invalidar aquellos actos que, por el desconocimiento de las formas, han vulnerado dicho derecho. ${ }^{56}$

Sin embargo, el régimen de nulidades del CGP está regido por la regla de la taxatividad, según la cual solamente se sancionan los eventos previstos en la ley, principalmente, en el artículo 133 del CGP. En ese orden de ideas, ningún acto procesal puede ser declarado nulo si la ley no prevé expresamente dicha sanción, por lo que no está permitida la aplicación analógica o extensiva de los supuestos de nulidad. ${ }^{57}$

Ahora bien, la regla de la taxatividad resulta muy cuestionable, en la medida en que existen bastantes irregularidades que representan graves vulneraciones al debido proceso y que no aparecen enlistadas en el catálogo diseñado por el legislador, ${ }^{58}$ como la que es objeto de estudio en el presente escrito.

Por ello, para sanear las irregularidades que resultan violatorias del derecho al debido proceso, pero que no se encuentran consagradas en el listado contenido en el CGP, podrá acudirse también a la acción de tutel ${ }^{59}$ destinada a proteger la violación de derechos fundamentales. Para ello, se dará aplicación a la teoría de transgresión del derecho al debido proceso, conforme a las causales de procedibilidad, generales y específicas, de la acción de tutela en contra de las providencias judiciales desarrolladas por la Corte Constitucional..$^{60}$ De todas maneras, para el caso que nos ocupa, en virtud de la subsidiariedad ${ }^{61}$ que caracteriza este mecanismo de amparo ${ }^{62}$ deberán agotarse de forma previa los mecanismos procesales con los que se cuente para atacar el acto procesal que, en este caso, es solamente el recurso de apelación.

No obstante, respecto de lo anterior, la Corte Suprema de Justicia, mediante sentencia del 21 de marzo de $2018,{ }^{63}$ providencia ya mencionada en este escrito y a la cual nos oponemos rotundamente, consideró que en el supuesto

56 Gallo, Recursos y nulidades procesales en el Código General del Proceso, op. cit.; Pardo, Tratado de Derecho Procesal Civil, op. cit.; Cardona, Los recursos ordinarios y extraordinarios en el derecho procesal civil, op. cit.

57 Henry Sanabria, Nulidad en el proceso civil, Bogotá, Universidad Externado de Colombia, 2011, pp. 124 y 163.

58 Idem.

59 Idem.

60 Desarrolladas, principalmente, en las siguientes sentencias: Corte Constitucional, Sentencia C-590 de 2005, M. P. Jaime Córdoba Triviño; Corte Constitucional, Sentencia SU-222 de 2016, M. P. María Victoria Calle Correa; Corte Constitucional, Sentencia SU-210 de 2017, M. P. José Antonio Cepeda Amarís; Corte Constitucional, sentencias SU-632 de 2017 y SU-116 de 2018, M. P. José Fernando Reyes Cuartas.

61 Corte Constitucional, Sentencia T-375 de 2018, M. P. Gloria Stella Ortiz Delgado.

62 Corte Constitucional, Sentencia C-590 de 2005, M. P. Jaime Córdoba Triviño; Corte Constitucional, Sentencia SU-222 de 2016, M. P. María Victoria Calle Correa; Corte Constitucional, Sentencia SU-210 de 2017, M. P. José Antonio Cepeda Amarís; Corte Constitucional, Sentencia SU-632 de 2017, M. P. José Fernando Reyes Cuartas; Corte Constitucional, Sentencia SU-116 de 2018, M. P. José Fernando Reyes Cuartas.

63 Corte Suprema de Justicia, Sala de Casación Civil, Sentencia STC3964-2018 del 21 de marzo de 2018, M. P. Luis Alfonso Rico Puerta. 
acá planteado, es decir, frente a la discrepancia entre el anuncio del sentido del fallo y la sentencia proferida por escrito, no podía afirmarse la ocurrencia de defectos procesales manifiestos, comoquiera que en el proceso civil las causales de nulidad son taxativas, a diferencia del proceso penal donde existe una nulidad virtual como sanción a toda actuación que resulte transgresora del debido proceso. Adicionalmente, la alta corporación afirmó que el mismo artículo 133 del CGP señala que las demás irregularidades del proceso se tendrán por subsanadas si no se alegan oportunamente por los mecanismos que la legislación procesal establece. ${ }^{64}$

En todo caso, sin perjuicio de la providencia mencionada, y por las razones anteriormente expuestas, ante el evento de incoherencia entre el anuncio del sentido del fallo y la sentencia dictada por escrito, consideramos que se tienen dos mecanismos con el fin de atacar la violación al debido proceso por el cambio del sentido del fallo: i) el recurso ordinario de apelación; y ii) la acción de tutela, como mecanismo subsidiario. Sin duda alguna, las alternativas con las que cuentan las partes son limitadas, teniendo en cuenta que dicha irregularidad resulta abiertamente transgresora del derecho al debido proceso, como se concluyó en acápites anteriores.

\section{Conclusiones}

Primera. No cualquier motivo puede resultar atendible para que el operador judicial opte por anunciar el sentido del fallo y dictar la sentencia por escrito. En efecto, las razones no deberán estar relacionadas con que el juez no tenga formado su convencimiento respecto de la decisión, ni que deba estudiar más a fondo el expediente, debido a que deberá expresar en el anuncio del sentido del fallo la parte resolutiva de la sentencia. Con el fin de que el juez despeje las dudas que tenga, la legislación prevé que este pueda decretar un receso de hasta dos horas en la audiencia, partiendo de la base de que debe asistir a la audiencia con el expediente plenamente estudiado.

Segunda. El anuncio del sentido del fallo consiste en que el juez indique, de forma concreta y específica: i) si accede o no a las pretensiones; ii) si accede parcialmente a las pretensiones, señalando de forma precisa a cuáles de ellas; y iii) si ha prosperado alguna excepción de mérito. En ese sentido, no podrán considerarse como anuncio del sentido del fallo aquellos pronunciamientos en los que se mencione escuetamente que se "accederá parcialmente a las pretensiones", o "se accederá a las pretensiones a las que haya lugar", o en los que, peor aún, no se indique nada.

64 Nicolás Salamanca, "La decisión de modificar el sentido del fallo y su impugnación”, en Boletín virtual del Departamento de Derecho Procesal, Bogotá, Universidad Externado de Colombia, 2018, en: https://procesal. uexternado.edu.co/la-decision-de-modificar-el-sentido-del-fallo-y-su-impugnacion/, fecha de consulta: 14 de abril de 2021. 
Tercera. La prerrogativa -desarrollada jurisprudencialmente- consistente en cambiar el sentido del fallo anunciado en audiencia en la sentencia escrita, con el fin de que prevalezca el derecho sustancial, resulta a nuestro juicio en contravía de la regulación que sobre el particular consagra la legislación procesal. Lo anterior, comoquiera que en el evento en el que el juez opte por dictar la sentencia por escrito, este acto procesal se tornará complejo y comprenderá: i) el anuncio del sentido del fallo; y ii) la sentencia. Así las cosas, estos dos actos procesales deberán ser concordantes y guardar armonía.

Cuarta. La prerrogativa de cambiar el sentido del fallo de forma excepcional también resulta violatoria del derecho al debido proceso, dado que es derecho de las partes tomar como definitivo el sentido de la decisión anunciada en audiencia, y que no sean sorprendidos de forma posterior con una decisión completamente diferente.

Quinta. En el supuesto en el que el operador judicial profiera un anuncio del sentido del fallo incompleto y no indique de forma precisa si accede o no a las pretensiones, $\mathrm{y}$, en caso de acceder parcialmente, no señale a cuáles ni en qué medida, cualquiera de las partes podrá solicitar su complementación, de acuerdo con el artículo 287 del CGP.

Sexta. En el evento en el que el administrador de justicia efectúe una variación del sentido del fallo, la parte que satisfaga el requisito de la legitimación para recurrir podrá interponer el correspondiente recurso de apelación, en aquellos procesos en los que este proceda. Ahora bien, y debido a que esta circunstancia no podrá ser alegada como causal de nulidad, también podrá presentarse, de forma subsidiaria, una acción de tutela por violación del debido proceso.

\section{Referencias}

Acosta, José, "Los hechos y actos procesales", en El proceso ante el tribunal internacional de justicia, Barcelona, Bosch, en http://vlex.com/vid/hechos-actosprocesales-281811, fecha de consulta: 17 de abril de 2021.

Álvarez, Marco Antonio, Cuestiones y opiniones. Acercamiento práctico al Código General del Proceso, Bogotá, Temis, 2017.

Azula, Jaime, Manual de Derecho Procesal, Tomo II. Parte General, Bogotá, Temis, 2015.

Azula, Jaime, Manual de derecho procesal, Tomo III. Procesos de conocimiento, Bogotá, Temis, 2016.

Calvinho, Gustavo, “El acto procedimental”, en G. Hernández, Derecho procesal moderno. Distintas visiones alrededor de esta disciplina, Bogotá, Universidad Externado de Colombia, 2013. DOI: https://doi.org/10.2307/j.ctvm7bb16.4 
Cardona, Pedro Pablo, Los recursos ordinarios y extraordinarios en el derecho procesal civil, Bogotá, Leyer, 2011.

Chiovenda, Giuseppe, Principios de derecho procesal civil, Madrid, Reus, 1922.

Daza, Alfonso, “Comentario II. ¿Se puede anular el sentido del fallo después de lo anunciado en la respectiva sentencia?", en Estudios críticos de jurisprudencia de la Corte Suprema de Justicia 2 (2013).

Echandía, Hernando, Tratado de derecho procesal civil. Parte General, Tomo III. De los actos procesales, Bogotá, Temis, 1963.

Escobar, Edgar, Los recursos en el Código General del Proceso, Medellín, Librería Jurídica Sánchez R., 2015.

Gallego, Carlos y Natalia Jaramillo, Teoría general del proceso. Actualizada en concordancia con la Ley 1564 de 2012, Bogotá, Ibáñez, 2018.

Gallo, Alejandro, Recursos y nulidades procesales en el Código General del Proceso, Bogotá, Leyer, 2018.

Guette, David, “El sentido del fallo contemplado en el artículo 373.5 del Código General del Proceso: lo inane de la figura", en Revista de Derecho Privado 36 (2019).

Hernández, Héctor, Estudios de derecho procesal civil general. Conforme con el Código General del Proceso, Bogotá, Leyer, 2016.

López, Hernán Fabio, Código General del Proceso. Parte General, Bogotá, Dupré, 2019.

Morales, Hernando, Curso de derecho procesal civil. Parte general, Bogotá, ABC, 1991.

Naranjo, Carlos, Derecho Procesal Civil. Parte General, Bogotá, Dike, 2016.

Osorio, Luis, Manual de Derecho Procesal Civil. Parte General, Bogotá, Leyer, 2016.

Oteiza, Eduardo, "El juez ante la tensión entre libertad e igualdad", en D. Agudelo et al. (dirs.), Derecho Procesal contemporáneo: perspectivas y desafíos, Medellín, Universidad de Medellín, 2017.

Pardo, Antonio, Tratado de Derecho Procesal Civil, Medellín, Editorial de la Universidad de Antioquia, 1956.

Parra, Jairo, Derecho procesal civil, Tomo I. Parte general, Bogotá, Temis, 1992.

Rocco, Ugo, Tratado de Derecho Procesal Civil. Parte Especial. Proceso de Cognición, Bogotá, Temis, 1972.

424 Rojas, Miguel Enrique, Lecciones de derecho procesal, Tomo 1. Teoría del proceso, Bogotá, Esaju, 2016. 
Rojas, Miguel Enrique, Lecciones de derecho procesal, Tomo 2. Procedimiento Civil, Bogotá, Esaju, 2017.

Salamanca, Nicolás, “La decisión de modificar el sentido del fallo y su impugnación", en Boletín virtual del Departamento de Derecho Procesal, Bogotá, Universidad Externado de Colombia, 2018, en https://procesal.uexternado. edu.co/la-decision-de-modificar-el-sentido-del-fallo-y-su-impugnacion/, fecha de consulta: 14 de abril de 2021.

Sanabria, Henry, Nulidad en el proceso civil, Bogotá, Universidad Externado de Colombia, 2011.

\section{Normas y jurisprudencia}

Congreso de la República de Colombia, Ley 1561 del 11 de julio de 2012, Por la cual se establece un proceso verbal especial para otorgar títulos de propiedad al poseedor material de bienes inmuebles urbanos y rurales de pequeña entidad económica, sanear la falsa tradición y se dictan otras disposiciones.

Congreso de la República de Colombia, Ley 1564 del 12 de julio de 2012, Por medio de la cual se expidió el Código General del Proceso.

Congreso de la República de Colombia, Ley 906 del 31 de agosto de 2000, Por la cual se expide el Código de Procedimiento Penal.

Corte Constitucional de Colombia, Sentencia C-124 de 2011, M. P. Luis Ernesto Vargas Silva.

Corte Constitucional de Colombia, Sentencia C-341 de 2014, M. P. Mauricio González Cuervo.

Corte Constitucional de Colombia, Sentencia C-543 de 2011, M. P. Humberto Antonio Sierra Porto.

Corte Constitucional de Colombia, Sentencia C-590 de 2005, M. P. Jaime Córdoba Triviño.

Corte Constitucional de Colombia, Sentencia C-641 de 2002, M. P. Rodrigo Escobar Gil.

Corte Constitucional de Colombia, Sentencia C-713 de 2008, M. P. Clara Inés Vargas Hernández.

Corte Constitucional de Colombia, Sentencia SU-116 de 2018, M. P. José Fernando Reyes Cuartas.

Corte Constitucional de Colombia, Sentencia SU-210 de 2017, M. P. José Antonio Cepeda Amarís. 
Corte Constitucional de Colombia, Sentencia SU-222 de 2016, M. P. María Victoria Calle Correa.

Corte Constitucional de Colombia, Sentencia SU-632 de 2017, M. P. José Fernando Reyes Cuartas.

Corte Constitucional de Colombia, Sentencia T-115 de 2018, M. P. Alberto Rojas Ríos.

Corte Constitucional de Colombia, Sentencia T-375 de 2018, M. P. Gloria Stella Ortiz Delgado.

Corte Suprema de Justicia de Colombia, Sala de Casación Civil, Auto del 4 de febrero de 2008, Exp. 2002-00537-00.

Corte Suprema de Justicia de Colombia, Sala de Casación Civil, Sentencia del 25 de septiembre de 2013, M. P. Fernando Alberto Castro Caballero, Rad. 40334.

Corte Suprema de Justicia de Colombia, Sala de Casación Civil, Sentencia STC14870-2017 del 20 de septiembre de 2017, M. P. Luis Armando Tolosa Villabona.

Corte Suprema de Justicia de Colombia, Sala de Casación Civil, Sentencia del 21 de marzo de 2018, M. P. Luis Alfonso Rico Puerta Rad. STC3984-2018.

Corte Suprema de Justicia de Colombia, Sala de Casación Civil, Sentencia del 21 de marzo de 2018, M. P. Luis Alfonso Rico Puerta, Rad. STC3984-2018.

Corte Suprema de Justicia de Colombia, Sala de Casación Laboral, Sentencia del 9 de mayo de 2018, M. P. Clara Cecilia Dueñas Quevedo, Rad. STL6431-2018.

Corte Suprema de Justicia de Colombia, Sala de Casación Penal, Sentencia del 3 de mayo de 2007, Rad. 26222.

Corte Suprema de Justicia de Colombia, Salvamento de Voto, M. P. Aroldo Wilson Quiroz Monsalvo, Rad. 11001-02-03-000-2018-00041-00. 